\title{
Effects of Blank-Qwerty-Touch Method and Performance of Business Education Students in Keyboarding in Federal College of Education, Kano, Nigeria
}

\author{
Ado Auwalu \\ S.S. Amoor \\ Department of Vocational and Technical Education, \\ Ahmadu Bello University, Zaria, Nigeria
}

\begin{abstract}
The study was carried out to determine the effects of blank-qwertytouch method on performance of business education students in keyboarding in Federal College of Education, Kano, Nigeria. The study had two objectives, two research questions, and two null hypotheses which were formulated and tested at 0.05 level of significance. A Quasi-experimental design was adopted for the study. The population of the study was 60 business education students who were admitted in 2015/2016 academic session in Federal College of Education, Kano, Nigeria. The sixty (60) students were used for the study as intact class. The instruments used to generate data for the study were two selfdesigned Keyboarding Skills Tests (Pre-test and Post-test). Mean and standard deviations were used to answer the stated research questions. Simple Regression Analysis (SRA) was used to test null hypotheses one, while t-test statistics was employed in testing null hypotheses two. From the results of the study, hypotheses one was rejected while hypothesis two was retained. The study showed that students in blank-QWERTY-touch teaching methods performed better than those in the conventional (QWERTY-touch) method, and gender did not show any significant difference in the performance of students taught keyboarding using blank-QWERTY-touch methods. It was concluded therefore that, blank-QWERTY-touch teaching method has effect on students' performance particularly at beginning of keyboarding training. Based on the findings, it was recommendation among others that, in order to make students develop high speed and accuracy, and ensure key position memorization at very beginning, keyboarding teachers should use the blankQWERTY-touch method.
\end{abstract}


Keywords: Business Education program, Keyboarding, blank-QWERTYtouch method and performance

\section{Introduction:}

Business education program is an area of study that exposes its recipients to diversify curricula, Ibrahim (2008), viewed it as that type of education that inculcates in its recipients' attitudes, knowledge, skills, and values that are required in the business world. This is a means of producing a healthy, literate self-reliant citizen that would create wealth for human development, when they become self-employed, thereby resulting to sustainable nation's development at large. Keyboarding is one of the fundamental subjects in business education. The National Commission for Colleges of Education (NCCE) in Nigeria recognized the subject as an important business education subject particularly in regard to achievement of objective five of NCE business education which targeted "to equip NCE graduates with the right skills that will enable them to engage in a life of work in the office as well as for self-employment” (NCCE, 2012 revised). The subject is purely manipulative skill whereby hands and fingers movements are trained to respond correctly and without conscious effort of the keyboard operator to key-in written or spoken words. If having effective keyboarding skills, NCE graduates will be able to type well in offices and business centers.

\section{Statement of the Problem}

Keyboarding is a core subject to all office technology and management education students, and there is a strong relationship between keyboarding and objectives of office education especially the goal of assuring all persons an opportunity to gain marketable skills prior to graduation. Keyboarding skills are designed to achieve successful mastery of keyboard - starting from manning home keys through the entire keyboard up to speed and accuracy as well as having the ability to type a readable and mailable document. This can be through constant drills on the use of home keys positions to recognition of the whole part of the keyboard. While students engaged in this training, their ability to type well will help them to come up with utmost speed and accuracy while their fingers remained up the keyboard and their eyes stare at the manuscript. Unfortunately, most of these students are violating the rules of keyboarding training leading them to start type-picking.

Several types of research works had shown that students' poor performance in keyboarding in Federal College of Education, Kano, Nigeria is attributed to ineffective use of teaching methods. However, some researches were conducted on teaching methods of keyboarding like hunt-and-peck, but their findings did not improved the performance of students in keyboarding in colleges of education, and what could be the reason is yet to be ascertained. 
This is so because data collected by the researcher from the college under study showed that, the analysis of business education students' performance in keyboarding for the period of five years $(2010$ - 2015) affirmed this statement. It was found that, out of 212 NCE II students only a maximum of 40.3\% and 32.2\% scored credit in keyboarding in 2015 and 2016 respectively.

On another hand, many people had perceived that keyboarding is a gender neutral, while some perceived that keyboarding is only a profession for female. The researcher went on to interact with both male and female graduates where it was observed that most of the female students developed anxiety in keyboarding training. Whereas some female students were observed performing better, their counter male students were observed to be having anxiety in both computers related keyboarding training and traditionally based ways. Some researchers like Lind, Morash and Stevens (2001) stated that keyboarding is not a gender neutral but a female profession. What is the actual fact about this perception especially in regards to use of methods is also yet to be ascertained. In the same vein, the researcher personally, observed that keyboarding is losing its image to the extent that many teachers are not really good in teaching keyboarding competence which in turn making students losing interest in the subject. Amoor (2014) stated that, these days' typewriting that involve manipulation, construction and demonstration is losing its values in the hierarchy of other business course like economics, accounting, and marketing to the extent that students are no longer speaking favorably about them. This led the researcher to went on and interact with business education students from colleges of education in Jigawa, Kano, and Zaria, and found that about $70 \%$ of these students could not display well-keyboarding skills prior to their graduation, one among the reasons given by the students was that teachers used inappropriate way of teaching keyboarding. Yohanna (2012) claimed that, most of the poorly displayed keyboarding skills by students were attributed to inappropriate use of methods while teaching.

Hence, the research is worried about the reported low performance of the college of education students in keyboarding and wonders if the adoption of blank-QWERTY-touch method could lead to an improvement of students' performance in the subject. It is based on these problems, therefore, the researcher carried out a research on effects of gamification Blank-QWERTYtouch method on the performance of business education students in keyboarding in Federal College of Education, Kano with aim of ascertaining their effects as newly developed methods. 


\section{Objectives of the Study}

The specific objectives were to;

1. determine the effect of the blank-QWERTY-touch method on the performance of business education students in keyboarding in Federal College of Education, Kano, Nigeria.

2. compare the differences in the mean performance of male and female business education students taught using blank-QWERTY-touch method in Federal College of Education, Kano, Nigeria.

\section{Research Questions}

The following research questions were formulated to guide the study:

1. what is the effect of the blank-QWERTY-touch method on the performance of business education students in keyboarding in Federal College of Education, Kano, Nigeria?

2. what is the difference in the mean performance of male and female business education students taught keyboarding blank-QWERTY-touch method in Federal College of Education, Kano, Nigeria?

\section{Research Hypotheses}

The following null hypotheses were formulated for the study.

$\mathrm{HO}_{1}$ : blank-QWERTY-touch method has no significant effect on performance of business education students in keyboarding in Federal College of Education, Kano, Nigeria

$\mathrm{HO}_{2}$ : there is no significant difference in the mean performance of male and female business education students taught keyboarding blank-QWERTYtouch method in Federal College of Education, Kano, Nigeria.

\section{Review of Related Literature}

Keyboarding is defined as a purely manipulative skill whereby hands and fingers are trained to move correctly and spontaneously with little or no conscious effort of an operator to key-in typewritten or spoken words. It involves manipulation of keys on a standard typewriter keyboard with emphasis on typed copy or output. The output is produced on paper at the same time as the input is provided. With the advent of personal computers, typewriters began to become wiped out. In fact, electric typewriters are partially in use. Electronic typewriters had an era of influence in the 1980s which is gradually decreasing, and virtually all input on a keyboard-like device in today's world is on a computer. The one remaining aspect is that, the computer keyboard is almost the same as the typewriter keyboard.

There are so many arguments on which method of teaching should a teacher use particularly to NCE keyboarding students. But, especially, opinions like that of Robert Cardian, Riofrio, Wawro and Perenson (2015) 
proved that, their performance in keyboarding improved using touch-cover and type-cover materials for typing. Khaled (2011) and Chua (2014) opined that, for effective keyboarding skills acquisition especially in this contemporary age of the computer, teachers have to emphasize on learner friendly methods as blank-QWERTY-touch method, because it can increase self-dependency, motivation and reduce learning boredoms in learners.

The blank-QWERTY-touch method is the use of blank keyboard to teach keyboarding. The method stimulates touch keying of characters by the keyboard operator. In order to stimulate students' ability to type well, the method is used to accelerate students' typing skills without looking at the keyboard. With using blank-QWERTY-touch, students can learn a gross motor skill and character position memorization by engaging into physically trained fingers without depending on keyboard characters. Fingers are trained up headedly in a systematic way to the extent that students take the positions of $\mathrm{A}-\mathrm{Z}$ letters without knowing their painted structures on the keyboard into their memories. The teacher teaches the students only with a specimen model of QWERTY in the classroom at the same time guiding them to identify the positions of the keys on the keyboard. The main purpose of the blankQWERTY-touch method is to boost in learners the ability to key in the data with his/her eyes off the keyboard, but, fixed on the manuscript (Hallows, 2002). Performance refers to what students achieve in their studies and how they cope with or accomplish different learning experiences given to them by their teachers. Ibrahim (2011) reported that in an educational institution, success is measured by academic performance, or how well students meet standards set out by the institution.

The concept of the blank-QWERTY-touch method was first initiated by Paul Shorey on January 20, 2015. The idea came up in order to improve an "eye up teaching keyboarding strategy". Naturally, many new typing students wanted to stare at their fingers constantly while typing. The founder was convinced that many teachers engaged on constant cautioning and shouting "eyes up" or worse "don't look at your fingers" to students' countless times. Generally speaking, these promptings have little effect on outcomes and only serve to agitate the class and make teaching very boring. The rationale behind avoiding the phrase "don't look at your fingers" was because, as a teacher, it is almost always better to focus on the positive behavior to expect rather than the negative behavior attempting to eliminate.

Schorey (2015) emphasized that, watching the finger by students reached for new keys helps make connections in the brain and will aid in developing the muscle memory that is trying to achieve. However, after the new keys are introduced, students need to be quickly weaned off of staring at their fingers so that they can focus on the text being written. The use of traditional keyboard prompted students to look up when they are seen staring 
at their fingers. Allowing students to continue practicing this attitude is not horrible if a teacher has high energy and able to roam the classroom constantly. But, for easiness, Schorey taught of the better alternative of using painted keyboarding method. The idea of hiding the letters but still allowing the teacher to observe students typing was what was needed to do. So, it was decided that the only option was to spray paint on the keyboards.

\section{Methodology}

A quasi-experimental design with post-test and control groups was adopted for this study. The population of the study was 60 male and female NCE I business education students who were admitted in 2015/2016 academic session in Federal College of Education, Kano, Nigeria using a self-designed Keyboarding Skills Test (KST) as instrument for data collection. The test had two parts; A and B. Part A was a warm up exercise which encompassed a combination of keyboard letters and punctuations, while part B contained exercise on sentences that comprised keyboard letters and punctuations as well. The researcher relied on contents of Keyboarding topic (Basic Keyboarding skills) taught in NCE One. after giving the treatment for 6 weeks, the post-test was administered to the students and lasted for 15 minutes. For the blank-QWERTY-touch group, a blank keyboard was used by students for the training and answering the post-test. The instruments were scored based on speed and accuracy with a total score of $100 \%$ which were divided into $75 \%$ for speed and 25\% for accuracy was used for marking the instruments. The instrument (Post-test) consisted of 154 words which the students were required to type twice within 10 minutes. That was, 308 words making 30 wpm in 10 minutes $(308 \div 10)$.

In analyzing the data collected, the two (2) research questions were analyzed using mean and standard deviation. The null hypothesis I was tested using Simple Regression Analysis (SRA), while null hypothesis II was tested using t-test, all at 0.05 level of significance.

For the research questions, the pass mark for the test scores was 50\%, a mean difference was used to determined effects and differences in the performance of students. Whereas the null hypotheses were retained where the calculated value was greater than or equal to the alpha value ( $\mathrm{P} \geq 0.05)$, and the hypotheses were rejected, where the calculated value was less than the Alpha value $(\mathrm{P}<0.05)$.

\section{PRESENTATION AND ANALYSIS OF DATA Answers to Research Questions}

The results of data used to answer the five research questions were presented in tables 1 and 2. 
Research Question One: What is the effect of Blank-QWERTYtouch method on the performance of business education students in keyboarding in Federal College of Education, Kano, Nigeria?

The analysis of data used to answer the research question two is presented in table 3.

Table 1: Mean and Standard Deviation of Effect of Blank-QWERTY-touch Method on the Performance of Business Education Students in Keyboarding

Variable

Blank-QWERTY-touch method

QWERTY-touch method
$\mathbf{N}$

30

30
SD.

5.08

4.93
Mean Difference

$53 \quad 5.08$

51
2

Source: Field Work, 2016

The results of Table 1 showed the effect of blank-QWERTY-touch method on the performance of business education students in keyboarding. The analysis revealed 30 Keyboarding students with a mean score of 53 and standard deviation of 5.08 for the blank-QWERTY-touch method, and 30 students with a mean score of 51 and a standard deviation of 4.93 for the QWERTY-touch method. This indicated a mean difference of 2 showing that blank-QWERTY-touch method had 2 difference effects over the QWERTY touch method. The summary of this result showed that, blank-QWERTYtouch method had an effect on students' performance in keyboarding. This means that, blank-QWERTY-touch method affects students' performance in keyboarding with an increased 2 effect. Therefore, it is indicated that BlankQWERTY-touch method was effective in teaching keyboarding students.

Research Question Two: What is the Difference in Mean Performance of Male and Female Business Education students taught Keyboarding using Blank-QWERTY-touch method in Federal College of Education, Kano, Nigeria?

The analysis of data used to answer the research question four is presented in table 2 .

Table 2: Mean and Standard Deviation of Performance of Male and Female Business

Education Students Taught Keyboarding Using Blank-QWERTY-touch Method

Model

Male

Female
$\mathbf{N}$

35

25
SD

54

58

$$
5.03
$$

16.10
Mean Difference

13

Source: Field Work, 2016

The results of Table 2 revealed the difference in the mean performance of male and female business education students taught keyboarding using blank-QWERTY-touch method. The table revealed that male students had a mean score of 54 with standard deviation of 5.03, while female students had a mean score of 58 with standard deviation of 16.10. The summary of the result 
revealed that, female and had higher mean percentage than their counter male taught keyboarding using blank-QWERTY-touch method (58 > 54) with an increased 4 effect. This means that, blank-QWERTY-touch method was more effective for female students than male students.

\section{Test of Null Hypotheses}

Null Hypothesis One: Blank-QWERTY-touch method has no significant effect on the performance of Business education students in Keyboarding in Federal College of Education, Kano, Nigeria.

Regression analysis used to test null hypothesis two is as presented in Tables 3 and 4.

Table 3: Regression Analysis on Effect of Blank-QWERTY-touch Method on Performance of Business Education students in Keyboarding

Model

Blank-QWERTYtouch method (Constant) QWERTY-touch method
Stand.

Error $t \quad$ r-cal $\quad \mathbf{R}^{2} \quad$ Adj.R Sig.

22.365

$8.179 \quad 2.734$

$0.539 \quad 0.152 \quad 3.541$

The regression analysis on Table 3 was to determine the effect of blank-QWERTY-touch method on the performance of business education students in keyboarding revealed a constant Beta value (blank-QWERTYtouch method) of 22.365 with the t-value of 2.734 against the coefficient value of 0.539 (QWERTY-touch method) and t-value of 0.152 . The r-value was 0.556 with $\mathrm{r}^{2}$-value of 0.309 and adjusted-r of 0.285 with a p-value of 0.000 . The result indicated that, gamification method had a variance of $31 \%$ $\left(r^{2} 0.309 \times 100\right)$ effect on students' performance in keyboarding. This means that for each single increase in blank-QWERTY-touch method practice, there was an increase of students' performance of $31 \%$. The observed $\mathrm{P}=0.000$ was less than the $\alpha$ value $(0.05)$ indicating a significant effect, therefore blankQWERTY-touch method had a significant effect on the performance of students in keyboarding in Federal College of Education, Kano, Nigeria. Hence, the null hypothesis was rejected.

Null Hypothesis Two: There is no significant difference in the mean performance of male and female business education students taught keyboarding using Blank-QWERTY-touch method in Federal College of Education, Kano, Nigeria.

Analysis used to test null hypothesis four is as presented in table 4. 
Table 4: t-test Analysis on Performance of Male and Female Business Education Students Taught Keyboarding Using Blank-QWERTY-touch Method

$\begin{array}{cccccc}\text { Model } & & \text { SD } & \text { df. } & \text { t-cal } & \text { Sig (2-tailed) } \\ \text { Male } & 54 & 5.03 & 33 & & \\ \text { Female } & 59 & 16.10 & 23 & 1.418 & 0.164 \\ & & \mathbf{P}>\mathbf{. 0 5} & & & \end{array}$

In Table 4, an independent t-test was conducted to compare mean difference between the performance of male and female students taught keyboarding using blank-QWERTY-touch method. The analysis revealed the mean (54) and standard deviation (5.03) for male students with degree of freedom of 33, and a mean of 59 and standard deviation of 16.10 for female students. The $\mathrm{t}$-value $(1.418, \mathrm{p}=0.164)$ was greater than the significant value (0.05). The result, therefore, indicated that, significant difference did not exist between the performance of male and that of female students taught keyboarding using the blank-QWERTY-touch method. Hence, the null hypothesis was retained.

\section{Discussions of Major Findings}

The result of the study revealed that blank-QWERTY-touch method had a positive effect on students' performance in keyboarding with a mean of $53 \%$, standard deviation of 5.08 and $\left.\mathrm{r}^{2}=0.309(31 \%) \quad \mathrm{p}=0.001\right\}$. This finding is in line with that of Schorey (2015) who found that, students who can't see the characters of their keyboards when keyboarding learned significantly faster than those who did not use. Lois (2004) also found that, students that used blank/covered keyboard to learn touch typing, learned to keyboard significantly faster than those who used a normal keyboard. He further reported that blank/covered keyboard was helpful in learning to the keyboard than otherwise.

In contrary, Amadi (2009) found that, demonstration method, huntand-peck method, touch method and self-directed methods are the major strategies for teaching Keyboarding skills. He further observed that sight and touch methods are the effective methods in teaching Keyboarding. Also, Byers (2010) found that students that used blank keyboard displayed more typing errors than those who typed using a normal keyboard. Byers, Anvey, and Zahner (2015) observed that, performance of students using covers for keyboarding was not encouraged because there was deterioration of students' ability in keyboarding proficiency.

The result of this study exposed that, there was no significance difference in the mean performance of male and female students taught keyboarding using the blank-QWERTY-touch method with 3\% $(\mathrm{p}=0.164)$ mean difference. Margarett, Lari, and Peter (2010) in their research found that, 
there was no significant difference on key stroking performance among female students who typed using a computer keyboard, and that typed using typewriter keyboard. They further affirmed that females typing speed and accuracy were measured and found that, in the two (2) different groups (software based method and covered method) there was no significant variation in the performance among the students (1\% variation). They also assured that, female students did not displayed any significant variation in speed $(\mathrm{p}=0.39)$ and accuracy $(\mathrm{p}=0.34)$ against their counter female in the other group ( $p=0.36$ and 0.34). Also, Anna, Deryl, and Antti (2016) found that, no significant difference in input performance among female students in touch-typing and software based typing. They further affirmed that an average entry rate of 57.8 WPM and 58.9WPM of each participant was shown. Furthermore, they affirmed that in measuring errors in the final input, no significant difference in the rate of errors with $0.76 \%$ and $0.47 \%$ for both groups respectively,

In contrary, Goehle (2013) found that, differences existed between the female and female students who learned to keyboard using blank-keyboard. Schottenbauer (2004) found that, women had experienced greater anxiety than men, particularly skilled based learning. Then, their academic achievement might not be significant compared to those of different learning.

\section{Conclusion}

Based on the outcome of this research, it was concluded that, blankQWERTY-touch had positively affected students' performance in keyboarding skills. Also, no significant difference existed between the performance of male and female students taught keyboarding using blankQWERTY-touch method.

\section{Recommendations}

Based on the outcome of the study, the following recommendations were made.

1. Blank-QWERTY-tough is good in teaching keyboarding at the very beginning of the course training. So, for proper key position memorization at the start, teachers should use the Blank-QWERTY-touch method at beginning of keyboarding training.

2. For blank-QWERTY-touch method to be effective, the administration of colleges of education should provide the ready-made blank-keyboard available in markets and or they should provide their computer laboratory(s) with Speed-skin cover (Keyboard cover for keys visualizing) so as to serve as a supplement to blank keyboards. 


\section{References:}

1. Amadi, T. (2009). Strategies for Effective Teaching of Typewriting in Colleges of Education in Enugu state. Unpublished Masters Thesis, University of Nigeria, Nsukka.

2. Amoor, S.S. (2014). Determinants of Colleges of Education Business Education Students' Choice of Office Technology and Management option in North-west Geo-Political Zone, Nigeria. (A Doctoral Dissertation), Ahmadu Bello University, Zaria, Nigeria. April, 2014. $27-29$.

3. Anna, C., Deryl, E., \& Antti, F.O. (2016). Increasing touchkeyboarding skills on children, Type-to-learn Software vs Covers. Retrieved on $13^{\text {th }}$ April 2015 from keyboarding.research.org.

4. Byers, E.M. (2010). Teaching and Learning Keyboarding. Tift County School System, Valdosta State University, United.

5. Byers, E.M., Aronvey, A. \& Zahran, J. (2015). Teaching and learning keyboarding. Valdosta University, USA.

6. Chua, H. (2014). Effects of gamification on learning experiences and outcomes. Temasek, Polytechnic, Singapore. Retrieved on $6^{\text {th }}$ October, 2015 from http://www.game/exp.html/pdf.

7. Goehle, G. (2013). Gamification and web-based homework. PRIMUS: Problems, Resources, and Issues in Mathematics Undergraduate Studies, 23(3), 234-246.

8. Hallows, J. (2002a). Proven Teaching Techniques for Teaching QWERTY Keyboarding. Retrieved on 6th November, 2015 from http://www.cwu.edu/sect/Idtech/keyboardig-techniques.Html.

9. Ibrahim, S. (2008). Business Education and Nigeria's National Development in the $21^{\text {st }}$ Century. Journal of Educational Research and Development.

10. Ibrahim, S. (2011) Impact of Accounting Background, Gender and Motivation on Performance of Business Education in Introductory Accounting in Federal Universities Nigeria: Unpublished Doctorate Dissertation Presented to the School of Post Graduate Studies, Ahmadu Bello University, Zaria.

11. Khaled, A. (2011), A comparison between teacher-directed and selfdirected instructions in keyboarding college students. Business Education Forum. 43, 12 -14.

12. Lind, M.C., Morash, M. \& Stevens, T. (2001). Girls' Troubles, Girls' Delinquency and Gender Responsiveness Programming. The University of Hawaii at Manna, United States of America. Retrieved on $7^{\text {th }}$ January, 2016 from www.programmingL.Hwii/delin/html 
13. Lois, N. (2004). Postsecondary school keyboarding students' speed and accuracy outcomes when using electronic equipment. Delta Pi Epsilon Journal. 35, 175 - 189.

14. Margarett, Lari \& Peter (2010). Are their Differences in Typing Performance and Typing Forces between Short and Long travel Keyboards?. In Press - Proceedings of the Human Factors and Ergonomics Society's 55th Annual Meeting.

15. NCCE, (2016). List of Colleges of Education in Nigeria. Retrieved on $5^{\text {th }}$ March, 2016, from www.ncceonline.edu.ng.

16. Nicholes, S. (2007). A user-Centered theoretical framework for meaningful gamification Games-Learning-Society. Retrieved on $5^{\text {th }}$ October, 2015 from http://scottnicholson.com/pubs/ meaningfulframework.pdf.

17. Richard, C. S. \& Norman, A. S. (1981). Educational Psychology (A Developmental Approach). $3^{\text {rd }}$ Edition, London: Addison-Wesley Publishing Company. Retrieved on $12^{\text {th }}$ March, 2016 from http://www.study.com.

18. Schorey, P. (2015). "eyes up" Teaching students not to look at their fingers or keyboard while typing. Retrieved on $2^{\text {nd }}$ August, 2015 from www.google.com/typinghomeblog. 